Research article

\title{
Egr-1 inhibits the expression of extracellular matrix genes in chondrocytes by TNF $\alpha$-induced MEK/ERK signalling
}

\author{
Jason S Rockel ${ }^{1,2}$, Suzanne M Bernier ${ }^{1,2}$ and Andrew Leask ${ }^{1,3}$
}

\author{
${ }^{1}$ Canadian Institutes of Health Research Group in Skeletal Development and Remodeling, Schulich School of Medicine \& Dentistry, The University of \\ Western Ontario, London, Ontario N6A 5C1, Canada \\ ${ }^{2}$ Department of Anatomy and Cell Biology, Schulich School of Medicine \& Dentistry, The University of Western Ontario, London, Ontario N6A 5C1, \\ Canada \\ ${ }^{3}$ Division of Oral Biology, Schulich School of Medicine \& Dentistry, The University of Western Ontario, London, Ontario N6A 5C1, Canada
}

Corresponding author: Andrew Leask, andrew.leask@schulich.uwo.ca

Received: 10 Nov 2008 Revisions requested: 5 Dec 2008 Revisions received: 8 Dec 2008 Accepted: 14 Jan 2009 Published: 14 Jan 2009

Arthritis Research \& Therapy 2009, 11:R8 (doi:10.1186/ar2595)

This article is online at: http://arthritis-research.com/content/11/1/R8

(c) 2009 Rockel et al.; licensee BioMed Central Ltd.

This is an open access article distributed under the terms of the Creative Commons Attribution License (http://creativecommons.org/licenses/by/2.0), which permits unrestricted use, distribution, and reproduction in any medium, provided the original work is properly cited.

\begin{abstract}
Introduction TNF $\alpha$ is increased in the synovial fluid of patients with rheumatoid arthritis and osteoarthritis. TNF $\alpha$ activates mitogen-activated kinase kinase (MEK)/extracellular regulated kinase (ERK) in chondrocytes; however, the overall functional relevance of MEK/ERK to TNF $\alpha$-regulated gene expression in chondrocytes is unknown.

Methods Chondrocytes were treated with TNF $\alpha$ with or without the MEK1/2 inhibitor U0126 for 24 hours. Microarray analysis and real-time PCR analyses were used to identify genes regulated by TNF $\alpha$ in a MEK1/2-dependent fashion. Promoter/ reporter, immunoblot, and electrophoretic mobility shift assays were used to identify transcription factors whose activity in response to TNF $\alpha$ was MEK1/2 dependent. Decoy oligodeoxynucleotides bearing consensus transcription factor binding sites were introduced into chondrocytes to determine the functionality of our results.

Results Approximately $20 \%$ of the genes regulated by TNF $\alpha$ in chondrocytes were sensitive to U0126. Transcript regulation of the cartilage-selective matrix genes Col2a1, Agc1 and Hapln1, and of the matrix metalloproteinase genes Mmp-12 and Mmp-9, were U0126 sensitive - whereas regulation of the inflammatory gene macrophage Csf-1 was U0126 insensitive. TNF $\alpha$-induced regulation of Sox9 and $\mathrm{NFKB}$ activity was also U0126 insensitive. Conversely, TNF $\alpha$-increased early growth response 1 (Egr-1) DNA binding was U0126 sensitive. Transfection of chondrocytes with cognate Egr-1 oligodeoxynucleotides attenuated the ability of TNF $\alpha$ to suppress Col2a1, Agc1 or Hapln1 mRNA expression.

Conclusions Our results suggest that MEK/ERK and Egr1 are required for TNF $\alpha$-regulated catabolic and anabolic genes of the cartilage extracellular matrix, and hence may represent potential targets for drug intervention in osteoarthritis or rheumatoid arthritis.
\end{abstract}

\section{Introduction}

Chondrocytes maintain articular cartilage through coordinated production and degradation of the extracellular matrix. Type II collagen, aggrecan, and link protein - encoded by the genes Col2a1, Agc1 and Hapln1, respectively - are major components of the articular cartilage extracellular matrix (ECM). Type II collagen is the major structural collagen of articular cartilage [1]. Aggrecan is the most abundant proteoglycan, and is responsible for resisting the compressive forces imposed on articulating joints [2]. Finally, link protein stabilizes the associ- ation of aggrecan with hyaluronic acid [3]. The expression of these ECM proteins is regulated by transcription factors within the nucleus promoting or inhibiting transcript production. Srytype high-mobility group box-9 (Sox9) is a regulatory transcription factor that binds DNA at specific sites within Col2a1, Agc1 and Hapln genes to induce their transcription [4-6].

In diseases such as rheumatoid arthritis and osteoarthritis there is a shift in the equilibrium in cartilage production and degradation towards catabolism. TNF $\alpha$, a potent inflammatory

Agc1: aggrecan 1; Col2a1: type II collagen $(\alpha)$; Csf-1: colony stimulating factor 1; DMSO: dimethyl sulfoxide; ECM: extracellular matrix; Egr: early growth response; ERK: extracellular regulated kinase; IFN: interferon; IL: interleukin; MEK: mitogen-activated kinase kinase; Mmp: matrix metalloproteinase; NF: nuclear factor; ODN: oligodeoxynucleotide; PCR: polymerase chain reaction; Sox: Sry-type high-mobility group box; TBST: Tris-buffered saline with Tween-20; TNF: tumour necrosis factor. 
mediator, is found at higher levels in the synovial fluid bathing articular cartilage in diseased joints compared with that of normal, healthy joints [7-9]. Previous work has shown that treatment of chondrocytes with TNF $\alpha$ downregulates the expression of Col2a1, Agc1 and Hapln1 without inducing apoptosis [10-13]. Furthermore, the activation of $\mathrm{NFKB}$ ) by TNF $\alpha$ signalling reduces Sox9 activity, possibly through competition for the transcriptional cofactor p300 [10,12]. Other signalling pathways are known to be activated by TNF $\alpha$, however, including the extracellular regulated kinase (ERK)/ mitogen-activated protein kinase pathway (reviewed in [14]).

TNF $\alpha$ initiates the activation of ERK/mitogen-activated protein kinase through the adaptor protein, Grb2, binding to the TNF $\alpha$ receptor 1, leading to activation of the ras/mitogen-activated kinase kinase (MEK)/ERK signalling cascade [15]. In immortalized chondrocytes and primary rat chondrocytes, ERK $1 / 2$ can be phosphorylated as early as 15 minutes of treatment with TNF $\alpha[10,11]$. Inhibition of MEK $1 / 2$ signalling can attenuate the decreases in Col2a1, Agc1 and Hapln1, as determined by northern blot analysis $[10,11]$. TNF $\alpha$ also regulates the activity of NFKB and Sox9 in chondrocytes [10,12]. TNF $\alpha$-induced NFKB DNA binding in immortalized chondrocytes is reduced by inhibition of MEK $1 / 2$ signalling [10]. TNF $\alpha$ may therefore regulate the expression of a subset of genes by alterations in the activity of these transcription factors in a MEK1/2-dependent manner.

Although some information is known about selected changes in chondrocyte gene expression in response to TNF $\alpha$-activated MEK/ERK signalling, the overall impact of this pathway on changes to the chondrocyte gene expression and the downstream transcriptional mechanisms mediating these changes has been poorly defined. We sought to identify the extent to which MEK/ERK may contribute to the overall changes in chondrocyte gene expression in response to TNF $\alpha$.

In the present study, we found that ERK1/2 undergoes multiple temporal phosphorylation events in response to TNF $\alpha$ induced MEK1/2 activation. We discovered that approximately $20 \%$ of the genes that changed at least 1.45 -fold with TNF $\alpha$ were dependent on MEK $1 / 2$ activation. A significant subset of these genes encoded proteins that localized to the extracellular space and had collagenase or hyaluronic acid binding activities. We determined that specific matrix metalloproteinases and cartilage-selective ECM transcript levels were regulated by MEK/ERK, while transcripts of the inflammatory gene macrophage colony stimulating factor 1 (Csf-1), were regulated in a MEK1/2-independent manner. Surprisingly, the activation of $N F \kappa B$ and the inhibition of Sox9 activity by $T N F \alpha$ were independent of MEK1/2. The DNA binding activity of the transcription factor early growth response 1 (Egr-1), however, was regulated by TNF $\alpha$-activated MEK1/2 signalling. Finally, we determined that Egr family members are responsible for the
TNF $\alpha$-induced, MEK-dependent reductions in mRNA transcripts. Egr-1 may therefore regulate a select number of genes in response to TNF $\alpha$-activated MEK/ERK signalling.

These findings reveal that MEK/ERK-dependent transcription factors that are downstream of TNF $\alpha$, such as Egr-1, may be targets for therapeutic intervention to treat the pathophysiology of arthritis without disrupting other potential positive effects of TNF $\alpha$.

\section{Materials and methods Primary chondrocyte culture}

Chondrocytes were isolated from the femoral condyles of neonatal ( 1 day old) rats as previously described [10]. The cartilage canals in newborn rats do not form in the femoral condyles until 5 days postnatal and radiographic signs of the secondary ossification centre do not appear until about 10 days postnatal [16]. Furthermore, to avoid hypertrophic chondrocytes, the upper two-thirds of the cartilage was taken. Cells were plated onto tissue culture plastic (Falcon, Franklin Lakes, NJ, USA) at a density of $\sim 2.5 \times 10^{4} \mathrm{cells} / \mathrm{cm}^{2}$. Under these conditions, the culture consists of an essentially pure chondrocyte population.

Monolayer chondrocyte cultures were grown in RPMI 1640 media (Invitrogen, Burlington, ON, Canada) supplemented with $5 \%$ foetal bovine serum, $100 \mathrm{U} / \mathrm{ml}$ penicillin, $100 \mu \mathrm{g} / \mathrm{ml}$ streptomycin and 1\% HEPES buffer (Invitrogen) until approximately $90 \%$ confluence was reached (6 to 7 days). Prior to treatment, chondrocytes were incubated in serum-free media overnight. For inhibitor studies, chondrocytes were pretreated with the selective MEK1/2 inhibitor U0126 (10 $\mu$ M; Promega, Thermo Fisher Scientific, Rockford, IL, USA) [17] for $30 \mathrm{~min}$ utes. As previously shown, U0126 has very low inhibitory activity towards other protein kinases [18]. Furthermore, previous studies in our laboratory have demonstrated that 24-hour treatment with $10 \mu \mathrm{M}$ U0126 had no significant effect on the cell morphology or organization in culture [11]. As controls, cultures were treated in parallel with dimethyl sulfoxide (DMSO) (vehicle for inhibitors), U0124 (10 $\mu \mathrm{M}$; Calbiochem, EMD Biosciences Inc., La Jolla, CA, USA) or the selective epidermal growth factor receptor inhibitor PD153035 (1 $\mu \mathrm{M}$; Calbiochem, EMD Biosciences Inc.) [19]. Cultures were then treated with human recombinant TNF $\alpha(30 \mathrm{ng} / \mathrm{ml}$; Endogen, Thermo Fisher Scientific) for 15 minutes to 24 hours.

\section{Antibodies}

Antibodies used in this study included anti-phospho-tyrosineERK1/2 (E4), anti-Egr-1 (588), anti- $\alpha$-tubulin (E-19), and antiNFkB p65 (C-20) antibodies (all from Santa Cruz Biotechnology, Santa Cruz, CA, USA). Horseradish peroxidase-conjugated goat-anti-rabbit or rabbit-anti goat secondary antibodies were obtained from Thermo Fisher Scientific. 


\section{Protein isolation and western blotting}

Nuclear and cytoplasmic extracts were isolated using a modified method of Dignam and colleagues [20], as previously described [10]. Total cell extracts were isolated using RIPA buffer as previously described [21]. Protein concentration was determined using the Pierce BCA Protein assay kit (Pierce, Thermo Fisher Scientific), as per the manufacturers' instructions. For western blotting, $20 \mu \mathrm{g}$ cytoplasmic protein was loaded into $10 \%$ polyacrylamide gels containing SDS and separated by electrophoresis. Proteins were transferred onto Protran $^{\mathrm{TM}}$ nitrocellulose membranes (Whatman, Inc., Florham Park, NJ, USA) by electroblotting and were stained with Ponceau $S$ to qualitatively determine equal loading of samples and efficient transfer of proteins. Membranes were blocked in 5\% nonfat milk (Carnation, North York, ON, Canada) in 0.05\% Tris-buffered saline containing $0.05 \%$ Tween-20 (TBST) for 1 hour followed by incubation with primary antibodies in blocking buffer overnight. Membranes were washed in TBST and incubated in 5\% milk-TBST with appropriate secondary antibody for 45 minutes to 1.5 hours. Membranes were then washed with TBST and rinsed in Tris-buffered saline prior to incubation in Supersignal West Pico Chemiluminescent Substrate (Pierce, Thermo Fisher Scientific) and exposed to Amersham Hyperfilm ECL (GE Healthcare Bio-Sciences Inc., Baie d'Urfé, QC, Canada). Membranes were stripped using $1 \mathrm{M}$ glycine, $\mathrm{pH} 2.5$, and washed using TBST prior to reprobing.

\section{RNA isolation}

Total RNA was isolated from cultures by Trizol (Invitrogen) followed by RNeasy clean-up (Qiagen, Mississauga, ON, Canada) as per the manufacturer's directions. Total RNA was quantified spectrophotometrically. High-quality RNA for use in the microarray analysis was confirmed by analysis in the Agilent 2100 Bioanalyzer (Agilent Technologies, Palo Alto, CA, USA).

\section{Microarray analysis}

Total mRNA $(10 \mu \mathrm{g})$ from two biological replicates of cells treated with DMSO, U0126, TNF $\alpha$ or U0126 and TNF $\alpha$, were amplified once and hybridized to RAT230_2.0 gene chips (Affymetrix, Santa Clara, CA, USA). Amplification, labelling, hybridization and detection were performed at the London Regional Genomics Centre (London, ON, Canada) according to the manufacturers' instructions.

\section{Microarray data and gene ontology analysis}

The raw expression values were imported into Genespring $G X$ 7.3 (Agilent Technologies). Raw expression values $<0.01$ were set to 0.01 and the normalization per chip was set to the 50th percentile. Relative gene expression of the 31,099 probe sets on the chip was determined by normalizing the raw expression values for each probe set to the DMSO control (= one-fold change for each probe set) from each independent experiment. To identify genes that were TNF $\alpha$-regulated, probe sets that were altered $\geq 1.45$ in DMSO/TNF $\alpha$-treated cultures compared with DMSO-treated cultures were determined for each independent experiment. Probe sets identified as being TNF $\alpha$ regulated in both independent experiments were selected for further analysis. Genes whose transcript levels changed $\geq 1.45$-fold were selected for study, as our microarray analysis revealed that aggrecan mRNA - a transcript previously shown to be TNF $\alpha$ sensitive [12] - was reduced approximately 1.45 -fold and thus served as a positive control establishing the validity of our microarray data.

To identify probe sets whose changes were altered by TNF $\alpha$ in a MEK1/2-dependent fashion, we normalized the fold change in gene expression of U0126/TNF $\alpha$-treated cultures to that of cultures treated with U0126 alone from both independent experiments. We determined probe sets that were altered $<1.45$-fold in response to DMSO/TNF $\alpha$ treatment, and hence were TNF $\alpha$ regulated in a U0126-sensitive fashion. The remainder of the genes on the lists of TNF $\alpha$-regulated probe sets were determined to be TNF $\alpha$ regulated and MEK independent. Probe sets identified as being TNF $\alpha$ regulated and MEK/ERK dependent or MEK/ERK independent in both independent experiments were selected for further analysis.

Genes were also identified whose basal expression was sensitive to U0126 alone. Probe sets altered $\geq 1.45$-fold in response to U0126 treatment relative to DMSO treatment were identified in both independent experiments. The limited number of genes that were altered with U0126 in both experiments $(89 / 31,099)$ prevented the use of meaningful cluster analysis, but nonetheless served as a potent indication of the selectivity of the U0126 inhibitor. The generated list was then compared with the list of genes changing $\geq 1.45$-fold with DMSO/TNF $\alpha$ to identify genes that were basal TNF $\alpha$ independent but MEK/ERK dependent and those genes that were both TNF $\alpha$ and basal MEK/ERK dependent.

The fold change in the transcript levels increased or decreased $\geq 1.45$-fold in both independent experiments was averaged. The generated lists of genes determined as TNF $\alpha$ activated MEK/ERK dependent and TNF $\alpha$-activated MEK/ ERK independent were analysed using the gene ontology browser in Genespring GX 7.3. Major cellular components and molecular functions subcategories of protein products from the list of genes were identified. The resulting list of cellular component ontologies was filtered such that a minimum of 10 genes must be in the initial group of annotated genes from the microarray and the resulting subcategory must be significantly represented $(P<0.05)$. Selected genes within the extracellular space ontology were then organized into subcategories that were significantly represented by the molecular function ontologies $(P<0.01)$.

\section{Quantitative real-time PCR}

Total RNA (25 ng) was amplified using the TaqMan One Step RT-PCR Master Mix (4309169; Applied Biosystems Inc., 
Streetsville, ON, Canada). Primer/probe sets to rat type II collagen (Col2a1, Rn00564954_m1), aggrecan 1 (Agc1, Rn00573424_m1), link protein (Hapln1, Rn00569884_m1), matrix metalloproteinase-9 (Mmp-9, Rn00579162_m1), matrix metalloproteinase-12 (Mmp-12, Rn00588640_m1), macrophage Csf-1 (Csf-1, Rn00576849_m1) and eukaryotic 18S rRNA (4352930E) were used to analyse relative transcript levels.

Reverse transcription and quantitative real-time $\mathrm{PCR}$ reactions were performed using the Prism 7900 HT Sequence Detector (Applied Biosystems Inc.). Samples were incubated at $48^{\circ} \mathrm{C}$ for 30 minutes to make cDNA templates. The resulting cDNA was amplified for 40 cycles. Cycles alternated between $95^{\circ} \mathrm{C}$ for 15 seconds and $60^{\circ} \mathrm{C}$ for 1 minute.

Results were analysed using SDS v2.1 software (Applied Biosystems Inc.). The $\Delta \Delta \mathrm{Ct}$ method was used to calculate gene expression levels relative to $18 \mathrm{~S}$ and normalized to vehicletreated cells. Data were log-transformed prior to analysis by one-way analysis of variance and Tukey's post-hoc test, paired $t$ tests and Student's $t$ tests, using Graphpad Software v. 4 (Graphpad Software, La Jolla, CA, USA).

\section{Transfection}

Confluent cell cultures were detached using trypsin-ethylenediamine tetraacetic acid (Invitrogen), pelleted, and resuspended in serum-free culture medium. Cells were then plated into 48-well dishes $\left(3.4 \times 10^{4}\right.$ cells/well) in $200 \mu \mathrm{l}$ and were transfected with equal amounts of reporter plasmids. The reporter plasmids used in this study included the $\kappa \mathrm{B}$ reporter (BD Biosciences, Mississauga, ON, Canada), comprising four tandem repeats of the $\kappa B$ response element upstream of the firefly luciferase reporter sequence and a type II collagen enhancer luciferase reporter (Sox9 reporter) containing four repeats of the 48-base-pair minimal enhancer of the type II collagen gene (pGL3 $(4 \times 48))$ [22]. Each minimal enhancer sequence contains a binding site for Sox9. Multiple repeats of the minimal enhancer are required for optimal firefly luciferase expression [23]. Cells were transfected with $20 \mu$ l serum-free media containing the equivalent of $0.156 \mu \mathrm{g}$ Sox 9 reporter or $N F_{\kappa} B$ reporter and $0.352 \mu$ Fugene 6 transfection reagent (Roche Diagnostics Corporation, Indianapolis, IN, USA). In all experiments, chondrocytes were co-transfected with a 0.002 $\mu \mathrm{g}$ renilla luciferase plasmid ( $\mathrm{pRL}-\mathrm{CMV}$; Thermo Fisher Scientific) to control for transfection efficiency. Cultures were transfected for 4 hours prior to addition of $200 \mu$ foetal bovine serum containing media.

After overnight incubation, the media was aspirated off from the transfected cultures and replaced with serum-free media. Cultures were treated as indicated above and collected using Passive Lysis Buffer (Thermo Fisher Scientific) as directed by the manufacturer. Luciferase activity was measured using the Dual Luciferase Assay System (Thermo Fisher Scientific) in an
L-max II microplate reader (Molecular Devices, Sunnyvale, CA, USA). Tanscription-factor-regulated firefly luciferase units were adjusted relative to constitutive cytomegalovirus-regulated renilla luciferase units obtained in control DMSO-treated, U0124-treated or U0126-treated cultures. Data were logtransformed prior to analysis by Student's $t$ tests and one-way analysis of variance using Graphpad Software v. 4 (Graphpad Software).

\section{Electrophoretic mobility shift assays}

Binding of nuclear protein complexes to the $\kappa \mathrm{B}$ or Egr-1 cognate elements was determined as previously described $[10,12]$. The double-stranded oligodeoxynucleotides (ODNs) containing the $\kappa \mathrm{B}$ cognate sequence (5'-AGTTGAGGGGACTTTCCCAGG-3'), the Egr cognate sequence (5'GGATCCAGCGGGGGCGAGCGGGGGCGA-3') and the Egr mutant sequence (5'-GGATCCAGCTAGGGCGAGCTAGGGCGA-3') were purchased from Santa Cruz Biotechnology. Competition assays were performed by adding 100-fold molar excess of unlabelled probe to the nuclear extract-labelled probe mixture. Antibody interference assays were performed by adding $2 \mu \mathrm{g}$ antibody against Egr1 (specific) or NFKB (nonspecific) 1 hour prior to the addition of nuclear extract to the buffered radiolabelled DNA. Samples were loaded into $4 \%$ polyacrylamide gels and were electrophoresed for 3.5 hours. Following electrophoresis, gels were dried and exposed to Amersham Hyperfilm-MP (GE Healthcare Bio-Sciences Inc.) at $-80^{\circ} \mathrm{C}$.

\section{Promoter analysis for putative transcription factor binding sites}

Upstream regions proximal to the transcriptional start site of the rat Col2a1 and Agc1 genes have been described previously $[24,25]$. Upstream regions from the transcriptional start site ( 5,000 base pairs) of the Rattus Norvegicus Col2a1 [GenBank:NM 012929.1] and Agc1 [GenBank:NM 022190] genes were obtained and analysed for putative transcription factor binding sites by TRANSFAC analysis [26].

\section{Oligodeoxynucleotide decoy assay}

Chondrocytes were plated at $1.2 \times 10^{6}$ cells/well in six-well culture dishes. Single stranded, phosphorothiol-modified ODNs were annealed by heating complementary ODNs to $98^{\circ} \mathrm{C}$ for 20 minutes followed by cooling to room temperature for 3 to 4 hours. Chondrocytes were transfected with $2 \mu \mathrm{M}$ double-stranded ODNs corresponding to the cognate EGR-1 binding sequence (5'-ggaTCCAGCGGGGGCGAGCGGGGgcgA-3') or the Egr mutant sequence (5'-ggaTCCAGCTAGGGCGAGCTAGGgcgA-3'; Sigma Genosys, Oakville, ON, CA) using 1\% HiPerfect transfection reagent (Qiagen), as per the manufacturer's instructions. (Lowercase letters indicate phosphorothiol-modified bases.) 
To optimize double-stranded ODN transfection conditions, chondrocytes were transfected cells with increasing concentrations of double-stranded, fluorescein-tagged and phosphorothiol-modified ODNs, and the cells were imaged by live-cell fluorescent microscopy (data not shown). Chondrocytes were allowed to grow for 24 hours in the presence of ODNs, after which cells were washed and cultured in serum-free RPMI media overnight. Chondrocytes were treated with TNF $\alpha$ for 24 hours, as described, and total RNA was collected for analysis by real-time PCR.

\section{Results}

\section{ERK1/2 is phosphorylated by TNF $\alpha$ in chondrocytes}

We have shown previously that TNF $\alpha$ induces ERK phosphorylation in primary articular chondrocytes 15 minutes post treatment [11]. To confirm and extend these results, we used western blot analysis to show that TNF $\alpha$ induced ERK1/2 phosphorylation 15 minutes post treatment (Figure 1), followed by a decrease in phosphorylation status (data not shown). ERK1/2 phosphorylation was again increased at 90 minutes post treatment (Figure 1). As anticipated, both the increases at 15 minutes and at 90 minutes could be inhibited by the MEK1/2 inhibitor U0126, but not its inactive isoform U0124 (Figure 1). Based on these data, we used U0126 as an inhibitor to assess the effect of blocking MEK1/2 on the mRNA expression pattern modulated by application of TNF $\alpha$ to chondrocytes.

\section{U0126 blocks part of the TNF $\alpha$-dependent gene expression changes in chondrocytes}

To investigate the global impact of U0126 on TNF $\alpha$-modulated gene expression in chondrocytes, we utilized microarrays to analyse changes in chondrocyte mRNA expression. Cells were serum-starved overnight and were treated with or without U0126 (10 $\mu \mathrm{M}, 30 \mathrm{~min})$ prior to addition of TNF $\alpha$ for 24 hours. Cells were treated with TNF $\alpha$ for 24 hours as previous data showed that this length of TNF $\alpha$ treatment was necessary to generate a TNF $\alpha$-mediated suppression of chondro- cyte matrix genes, owing to the stability of chondrocyte matrix gene mRNAs [27-30].

Microarray analysis from two independent experiments determined that 629 genes were regulated by TNF $\alpha$ signalling in both sets of experiments by at least 1.45 -fold, the majority of which were increased in response to TNF $\alpha$ (Figure 2). Of these genes, alterations of $138(\sim 22 \%)$ were attenuated with U0126. Furthermore, of the remaining genes that were not regulated by $T N F \alpha, 62$ genes were regulated by U0126 alone, indicating that basal MEK/ERK activity may also play a role in chondrocyte gene regulation. Complete microarray data have been deposited in the Gene Expression Omnibus public repository [GEO:GSE14402].

\section{Selective extracellular matrix and proteinase genes are regulated by TNF $\alpha$-induced MEK/ERK signalling}

We further analysed the lists of genes that were induced by TNF $\alpha$ using specific gene ontologies. Analysis of the list of TNF $\alpha$-induced, MEK/ERK-dependent and MEK/ERK-independent probe sets indicated that there was significant representation $(P<0.05)$ of genes whose protein products localize to the extracellular space within both lists (Table 1). Further analysis of the list of TNF $\alpha$-regulated, MEK/ERK-dependent genes - whose products are found in the extracellular space - indicated that some of these genes were significantly categorized by the molecular function of their protein products into categories that included hyaluronic acid binding activity (including Agc1 and Hapln1) and proteinase activity (including Mmp-9 and Mmp-12). Analysis of the TNF $\alpha$-regulated, MEK/ ERK-independent list of genes whose protein products were localized to the extracellular space determined that many of the protein products of these genes were involved in a variety of activities, including chemokine/cytokine activity - including macrophage Csf-1 - and various protease activities. The inflammatory genes, however, appeared to be primarily U0126 insensitive.

Figure 1
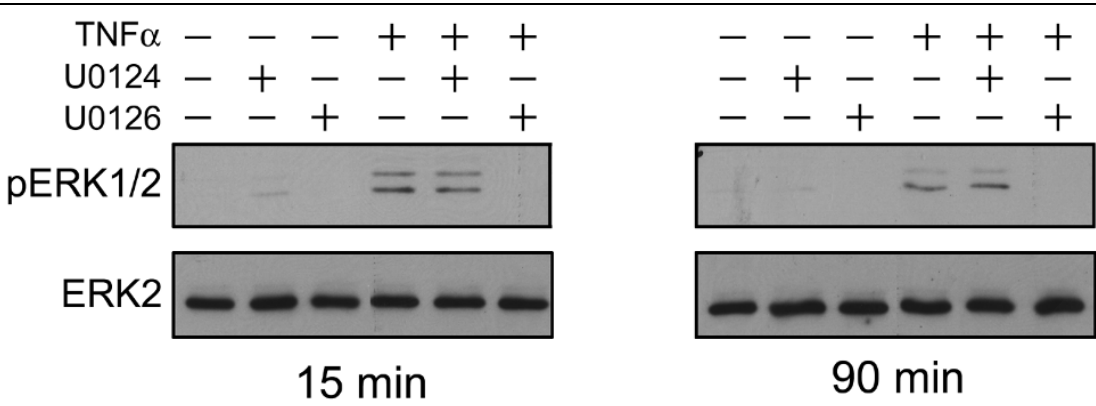

Multiple ERK1/2 phosphorylation events are dependent on MEK1/2 signalling. Chondrocytes were pretreated with dimethyl sulfoxide, U0124 $(10 \mu \mathrm{M})$ or the active mitogen-activated kinase kinase (MEK) 1/2 inhibitor, U0126 (10 $\mu \mathrm{M})$ for 30 minutes prior to TNF $\alpha$ treatment for 15 minutes or 90 minutes. Cytoplasmic extracts $(20 \mu \mathrm{g})$ were resolved on $10 \%$ polyacrylamide gels and were immunoblotted for pY-extracellular regulated kinase (ERK) $1 / 2$ or total ERK2. Immunoblots are representative of three independent experiments. 
Figure 2

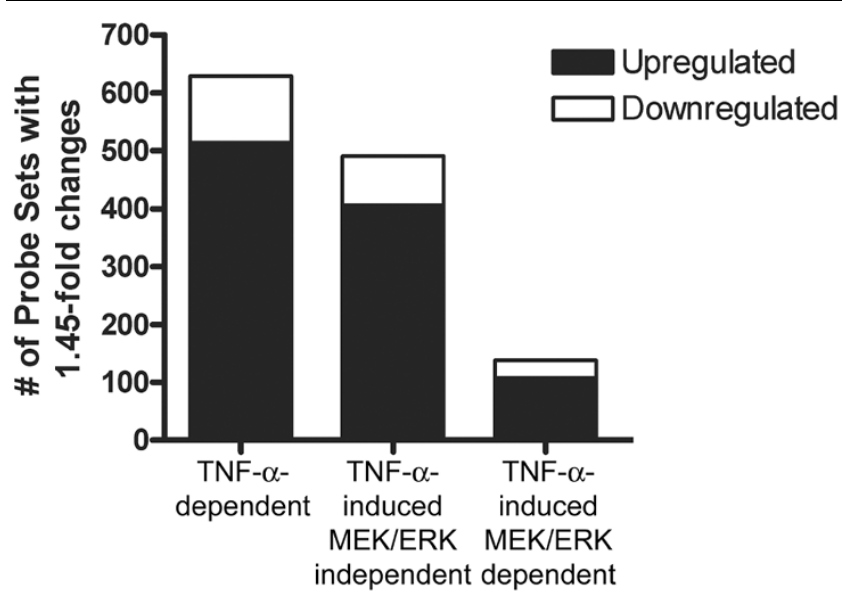

Activated MEK/ERK signalling regulates a portion of genes regulated by TNF $\alpha$ signalling. Total mRNA from two independent experiments of primary chondrocytes pretreated with dimethyl sulfoxide or U0126 for 30 minutes followed by treatment with vehicle or TNF $\alpha$ for 24 hours was subjected to microarray analysis. The number of probe sets changing expression $\geq 1.45$-fold in TNF $\alpha$-treated cells (first bar), and the distribution of those changes that are dependent (second bar) or independent (third bar) of mitogen-activated kinase kinase (MEK) 1/ 2 activity. Probe sets showing $\geq 1.45$-fold fold changes with U0126 treatment alone are indicated by the last bar. In order for a probe set to be counted in these categories, the gene needed to be increased or decreased in the same direction $\geq 1.45$-fold in both of the two independent experiments. For each bar, the number of genes downregulated (white) and upregulated (black) are indicated. ERK, extracellular regulated kinase.

To validate the changes in gene expression in response to TNF $\alpha$-induced MEK/ERK signalling determined by the microarray analysis, we identified the relative changes in transcript levels of the extracellular matrix components Agc1, Hapln1, and Col2a1, proteases Mmp-9 and Mmp-12, as well as the inflammatory cytokine macrophage Csf-1 (Figure 3). TNF $\alpha$ decreased Agc1 and Hapln1 (Figure 3a, b) and increased Mmp-9 and Mmp-12 (Figure 3e, f) in a MEK/ERK-dependent manner. In addition, Col2a1 - a gene not identified as MEK/ ERK sensitive by microarray analysis - was also determined to be MEK/ERK sensitive (Figure 3c). Pretreatment with U0126, however, only partially attenuated the TNF $\alpha$-induced reductions in Agc1, Hapln1 and Col2a1 transcript levels - to a level only moderately, but not significantly, lower than control treated cultures, suggesting the possible involvement of other pathways (Figure $3 a$ to 3c). Conversely, TNF $\alpha$-induced increases in macrophage Csf-1 were independent of MEK/ ERK signalling (Figure 3d). As anticipated, the inactive U0126 analogue U0124 had no effect in any of the assays tested. Taken together, these results suggest that U0126 may attenuate the changes in chondrocyte gene expression towards a catabolic phenotype while allowing for inflammatory processes to be undisturbed.

\section{Regulation of Sox9 and NF $\kappa B$ activity by TNF $\alpha$ are independent of MEK/ERK signalling}

We next wanted to determine the possible molecular basis for TNF $\alpha$-modulated, U0126-sensitive gene expression. First, we investigated whether U0126 affected the ability of TNF $\alpha$ to regulate the activity of the transcription factors Sox 9 and $\mathrm{NF}_{\kappa \mathrm{B}}$, which are known to be regulated by TNF $\alpha$ in chondrocytes $[10,12]$. As expected, TNF $\alpha$ significantly reduced the level of Sox 9 activity and increased the level of NFKB activity in chondrocytes $(P<0.01$; Figure $4 a, b)$. There was no significant effect, however, on the level of inhibition or the induction of Sox9 and NFKB activity, respectively, by either U0124 or U0126 ( $P>0.05$; Figure 4a, b). Furthermore, we found that TNF $\alpha$-induced DNA binding of NFKB was reduced by pretreatment with DMSO (vehicle for the inhibitors) and was not further reduced by pretreatment with U0124, U0126 or the selective epidermal growth factor receptor inhibitor, PD153035 (Figure 4c). These results indicate that transcription factors other than Sox 9 and NFKB are targets of TNF $\alpha$ induced MEK/ERK signalling.

\section{Egr-1 DNA binding is increased in a TNF $\alpha$-induced MEK/ ERK-dependent manner}

To determine additional, candidate transcription factors that may regulated by MEK/ERK, we considered that Egr-1 is a known early target of MEK/ERK signalling and that IL-1 induction of Egr-1 inhibits the activity of the human type II collagen proximal promoter [31]. We therefore focused the remainder of our study on Egr-1 and its possible role in regulating U0126-sensitive TNF $\alpha$-induced genes.

We identified multiple putative Egr-1 binding sites in the promoter regions of the rat $\mathrm{Col} 2 \mathrm{a} 1$ and Agc1 genes that were proximal to the transcription initiation site and overlapped with putative Sp1 binding sites (Figure 5). TNF $\alpha$ treatment of chondrocytes over 24 hours did not alter the Egr-1 protein levels, and neither did treatment for 90 minutes alter the nuclear localization of Egr-1 (data not shown).

We then used electrophoretic mobility shift assays to investigate whether the binding of Egr-1 to DNA was dependent on TNF $\alpha$-induced MEK/ERK signalling. Nuclear extracts from chondrocytes treated with TNF $\alpha$ for 90 minutes increased the DNA binding of two complexes containing Egr-1 to an Egr consensus DNA binding site (Figure 6, arrowheads). Both complexes were reduced when extracts were preincubated with a 100-fold molar excess of double-stranded cold Egr consensus ODNs, but not with cold mutant Egr ODNs or NFKB consensus ODNs (Figure 6, arrowheads). Compared with preincubation of extracts with the anti-NFKB p65 antibody, preincubation of extracts with the anti-Egr-1 antibody specifically reduced the DNA-protein complexes attributed by the Egr consensus ODN competition studies to be a result of Egr/ DNA binding (Figure 6, arrowheads). Pretreatment of cells with U0126 attenuated the increase in complex formation of 
Table 1

Extracellular space genes regulated at least 1.45 -fold by TNF $\alpha^{a}$

\begin{tabular}{|c|c|c|c|c|c|}
\hline \multirow[t]{2}{*}{ Gene } & \multirow[t]{2}{*}{ Accession number } & \multirow[t]{2}{*}{ Description } & \multicolumn{2}{|l|}{ Fold change } & \multirow{2}{*}{$\begin{array}{l}\text { Basal MEK/ERK } \\
\text { dependent }\end{array}$} \\
\hline & & & U0126 TNF & TNF + U0126 & \\
\hline
\end{tabular}

TNF $\alpha$-regulated MEK/ERK dependent

$\begin{array}{ll}\text { Agc1 } & \text { [GenBank:NM 022190] } \\ \text { Hapln1 } & \text { [GenBank:NM 019189] } \\ & \\ \text { Mmp-12 } & \text { [GenBank:NM 053963] } \\ \text { Mmp-9 } & \text { [GenBank:NM 031055] } \\ \text { Arts1, ERAP1, } & \\ \text { Appils } & \\ \text { C4bpa } & \end{array}$

Hyaluronic acid binding activity

$\begin{array}{llll}\text { Aggrecan 1 } & 1.14 & 0.68 & 1.08 \\ \begin{array}{l}\text { Hyaluronan and proteoglycan } \\ \text { link protein 1 }\end{array} & 1.15 & 0.65 & 0.96\end{array}$

Collagenase or metallopeptidase activity

Matrix metallopeptidase 12

$\begin{array}{lll}0.67 & 2.92 & 0.93\end{array}$

Matrix metallopeptidase 9

$0.87 \quad 1.89 \quad 1.01$

Metallopeptidase activity

$\begin{array}{llll}\text { Type } 1 \text { TNF receptor shedding } & 1.33 & 1.78 & 1.55\end{array}$ aminopeptidase regulator

\section{Complement binding}

Complement component 4 binding protein, alpha

$$
1.01 \quad 2.19 \quad 1.35
$$

Others

Amigo2

[GenBank:NM 182816]

Cacna2d3

[GenBank:NM 175595]

Cd68 (predicted)

[GenBank:NM 001031638]

Cgref1, Cgr11

[GenBank:NM 139087]

Cyp4b1

[GenBank:NM 016999]

Gm1960, Cinc2, [GenBank:NM 138522] Cinc-2

TNF $\alpha$-regulated MEK/ERK independent

Adam17; TACE

[GenBank:NM 020306]

Mmp13

[GenBank:XM 343345]

Ctsc

Serpinb2, Pai2a

[GenBank:NM 017097]

Plat, tPA, PATISS

Plau, UPAM

[GenBank:NM 013151]

C1s, r-gsp

[GenBank:NM 013085]

[GenBank:NM 138900], [GenBank:XM 575664]

Cpxm1 (predicted)

[GenBank:XM 215840]
Adhesion molecule with Ig-like domain 2

Calcium channel, voltagedependent, $\alpha_{2} / \delta_{3}$ subunit

CD68 antigen

Cell growth regulator with EF hand domain 1

Cytochrome P450, family 4, subfamily b, polypeptide 1

Gene model 1960 (NCBI)

$\begin{array}{lll}0.94 & 2.38 & 1.27\end{array}$

Peptidase activity

A disintegrin and metalloproteinase domain 17 (TNF, alpha, converting enzyme)

Matrix metallopeptidase 13

$0.33 \quad 6.80 \quad 1.10$

Cathepsin C

$\begin{array}{lll}1.18 & 2.84 & 1.72\end{array}$

Serine (or cysteine) proteinase inhibitor, clade B, member 2

Plasminogen activator, tissue

$\begin{array}{lll}0.75 & 3.47 & 1.68\end{array}$

Plasminogen activator,

$0.94 \quad 3.22 \quad 1.56$ urokinase

$\begin{array}{lll}1.36 & 2.23 & 2.87\end{array}$

Complement component $1, \mathrm{~s} \quad 1.05 \quad 1.98 \quad 1.88$ subcomponent

Carboxypeptidase $\times 1$ (M14 family) (predicted) 
Table 1 (Continued)

Extracellular space genes regulated at least 1.45 -fold by TNF $\alpha^{a}$

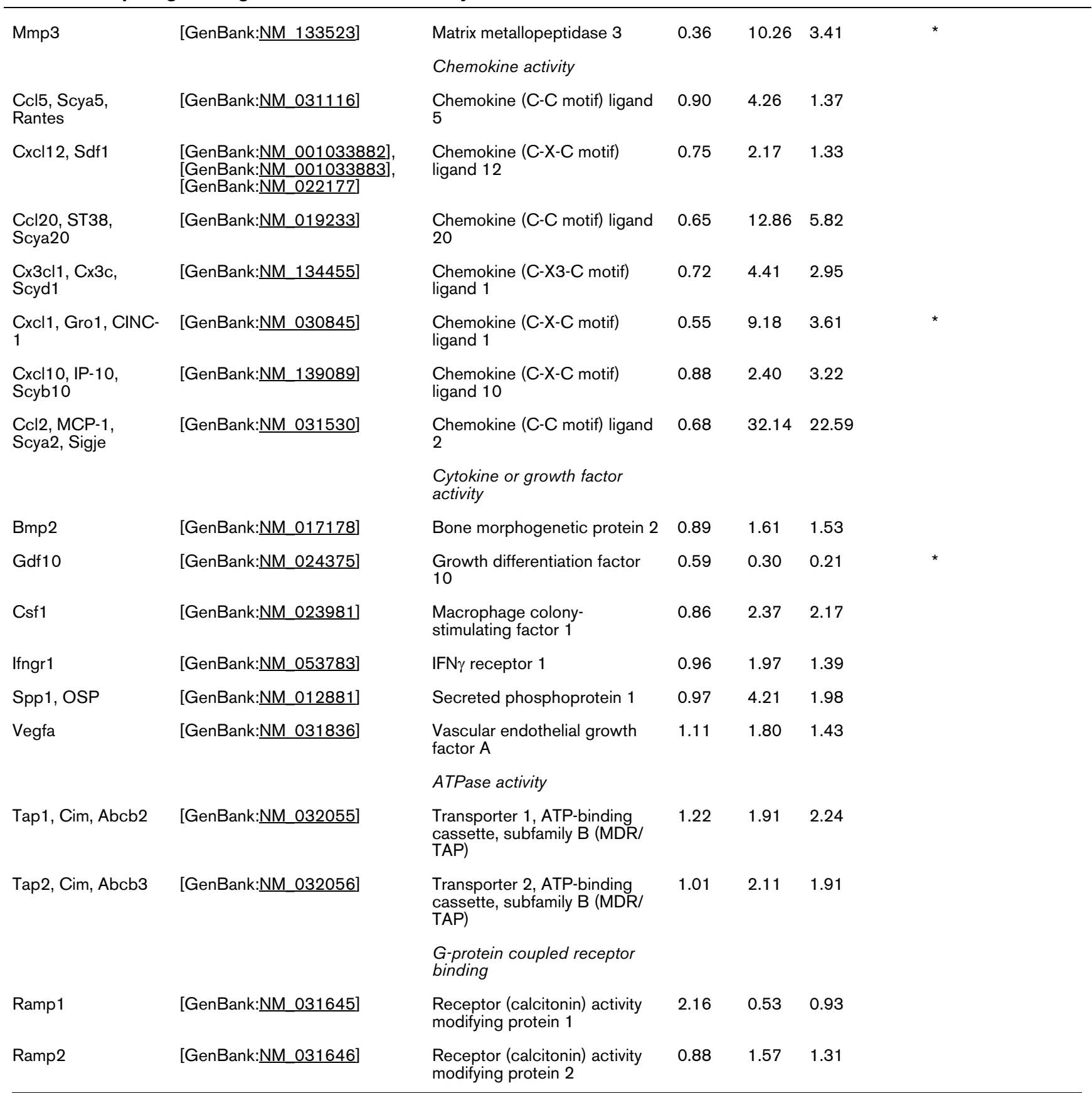

aGenes separated into molecular function subcategories represented in the list of gene changing at least 1.45 -fold by TNF $\alpha$ as either mitogenactivated kinase kinase (MEK)/extracellular regulated kinase (ERK) dependent or MEK/ERK independent. Specifically defined subcategories were identified in the molecular function gene ontology as significantly represented $(P<0.01)$ within the MEK/ERK dependent or MEK/ERK independent lists.

both identified complexes. The binding of the identified complexes to DNA was inhibited by pretreatment with U0126 but not with U0124, indicating DNA binding of Egr-1 is dependent on TNF $\alpha$-activated MEK/ERK signalling.

\section{Egr family DNA binding is responsible for decreased chondrocyte matrix gene expression}

To determine whether decreases in chondrocyte selective matrix gene expression in response to TNF $\alpha$ were dependent on the genomic DNA binding activity of Egr family members, we transfected cells with double-stranded ODNs containing 

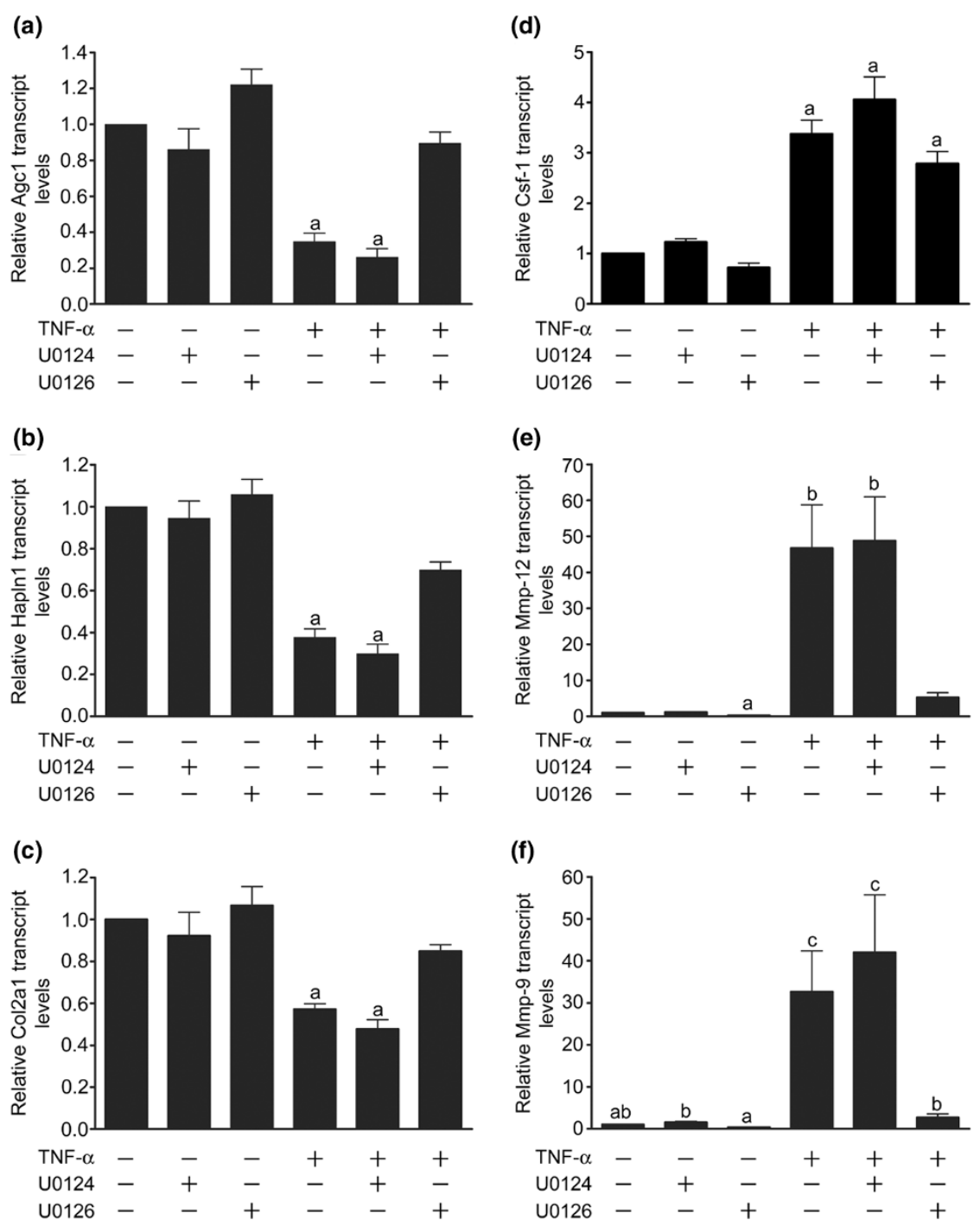

TNF $\alpha$ regulates cartilage-selective matrix genes and proteinases in a MEK1/2-dependent manner. Chondrocytes were pretreated with dimethyl sulfoxide, U0124 $(10 \mu \mathrm{M})$ or $\mathrm{U} 0126(10 \mu \mathrm{M})$ for 30 minutes prior to treatment with TNF $\alpha$ for 24 hours. Total mRNA was collected and analysed for (a) aggrecan (Agc1), (b) link protein (Hapln1), (c) type II collagen (Col2a1), (d) macrophage colony-stimulating factor 1 (Csf-1), (e) matrix metalloproteinase-12 (Mmp-12) and (f) matrix metalloproteinase-9 (Mmp-9), and 18S transcript levels by quantitative real-time PCR. (a) to (f) Data were analysed by the $\triangle \Delta C T$ method to acquire matrix gene transcript levels relative to $18 \mathrm{~S}$ transcript levels and were normalized to DMSO-treated cells. Data were log-transformed prior to analysis by one-way analysis of variance followed by Tukey's post-hoc tests. Unlabelled bars or bars labelled with the same lowercase letter are not significantly different $(P>0.05)$. Data are expressed as the mean \pm standard error of five independent experiments - except (c), four independent experiments. MEK, mitogen-activated kinase kinase.

phosphorothiolate modifications corresponding to the cognate and a mutated form of the Egr-DNA binding sequence (Figure 7). Transfection of cells with mutant double-stranded ODNs did not disrupt decreases induced by TNF $\alpha$ to Col2a1, Agc1 or Hapln1 transcript levels. Transfection using the cognate Egr double-stranded ODNs, however, attenuated the decreases in transcript levels of Col2a1, Agc1 and Hapln1 by TNF $\alpha$. Egr-containing complexes, probably that include Egr-1, are therefore responsible for the reduced transcript levels of cartilage selective matrix genes in response to TNF $\alpha$ in chondrocytes.

\section{Discussion}

In the present study, we used the MEK1/2 inhibitor U0126 to identify the possible contribution of the MEK/ERK signalling pathway to changes in chondrocyte gene expression in response to TNF $\alpha$. Inspection of the $\sim 20 \%$ of TNF $\alpha$-regulated chondrocyte mRNAs whose expression was modulated by MEK1/2 revealed a significant representation of genes whose protein products localized to the extracellular space, and had proteinase activity (for example, Mmp-9 and Mmp-12, which were induced by TNF $\alpha$ ) or hyaluronic acid binding activity (for example, the matrix-associated genes Agc1 and Hapln1, 
(a)

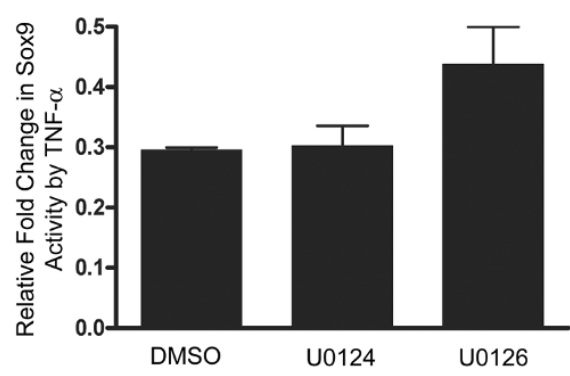

(b)

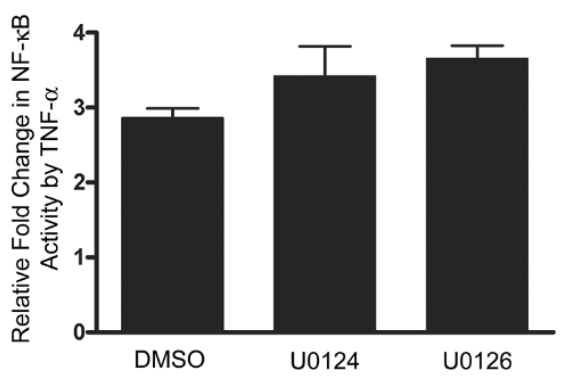

(c) $\mathrm{DMSO}-+-+-----$

$\mathrm{U} 0124--\quad-+--+-$

U0126 - - - - - + - - +

$\mathrm{PD} 153035-\infty-\infty-\infty+$

TNF- $\alpha--++--\infty++$
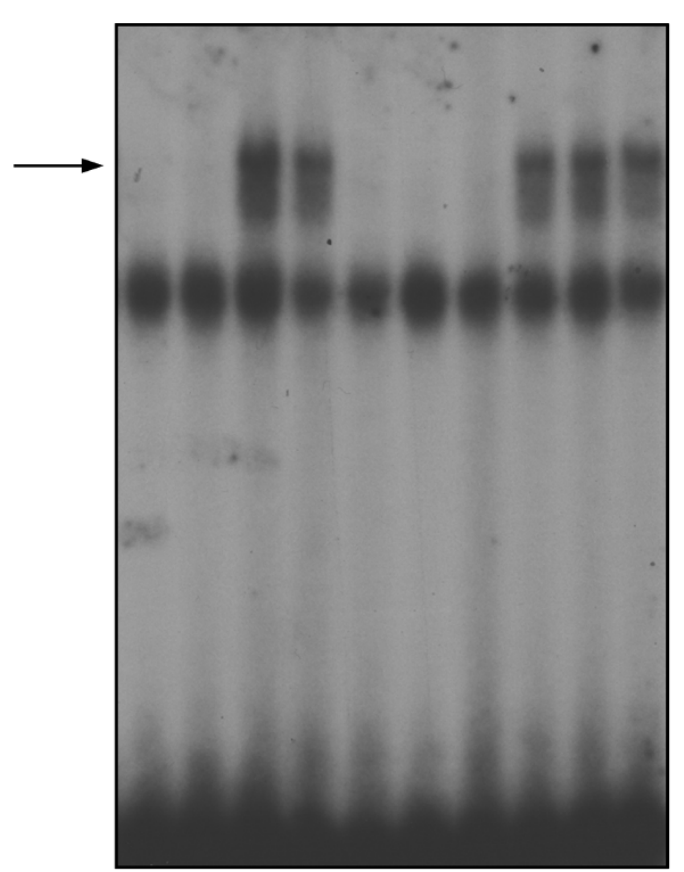

TNF $\alpha$-induced changes to Sox 9 and NFKB functional activity are independent of MEK1/2 activity. Chondrocytes transfected with (a) Sox 9 or (b) NFKB reporters were pretreated with dimethyl sulfoxide (DMSO), U0124 $(10 \mu \mathrm{M})$ or U0126 $(10 \mu \mathrm{M})$ for 30 minutes followed by treatment with TNF $\alpha(30 \mathrm{ng} / \mathrm{ml})$ for 24 hours. Data are ratios of (a) Sox9-regulated or (b) NFKB-regulated firefly luciferase units to constitutive cytomegalovirus-regulated renilla luciferase units in TNF $\alpha$-treated cultures normalized to their respective DMSO-treated, U0124-treated or U0126 control-treated cultures. Data were log-transformed prior to analysis by paired $t$ tests to determine significant reporter regulation by TNF $\alpha$, followed by one-way analysis of variance to determine significant differences between the effects of DMSO, U0124 or U0126 pretreatment on TNF $\alpha$-regulated reporter activity. Data are expressed as the mean \pm standard error of four independent experiments. (c) Cells were pretreated with vehicle, DMSO, U0124 $(10 \mu \mathrm{M})$ or $\mathrm{U} 0126(10 \mu \mathrm{M})$, or PD153035 $(1 \mu \mathrm{M})$ for 30 minutes followed by treatment with TNF $\alpha(30 \mathrm{ng} / \mathrm{ml})$ for 24 hours. Nuclear extracts $(10 \mu \mathrm{g})$ were incubated with ${ }^{32} \mathrm{P}$-radiolabelled $\kappa \mathrm{B}$-consensus DNA. Resulting protein-DNA complexes were resolved on $4 \%$ polyacrylamide gels and exposed by autoradiography. Arrow, NFKB p65-containing protein-DNA complexes, as previously described [12]. The autoradiograph displayed is representative of three independent experiments.

which were suppressed by TNF $\alpha$ ). Mmp-9 and Mmp-12 cleave selective proteoglycans and collagens [32-34] while Mmp-9 is also an important mediator of inflammatory arthritis [35]. Furthermore, we have shown that increases in transcripts encoding proinflammatory genes, such as macrophage Csf-1, were U0126 insensitive. Collectively these results suggest the intriguing notion that, compared with the TNF $\alpha$-regulated transcript levels of genes involved in inflammation, TNF $\alpha$-induced matrix catabolism may selectively require MEK/ERK. Further efforts will be required to assess whether similar mechanisms might operate in adult rat or human chondrocytes, or in cells isolated from patients with arthritis. Nonetheless, our data - for the first time - suggest that MEK inhibitors modify the excessive matrix degradation in arthritis.

Consistent with TNF $\alpha$-induced increases in macrophage Csf1 transcript levels observed in this study, macrophage Csf-1 protein levels are also induced by TNF $\alpha$ in chondrocytes [36]. In rat articular chondrocytes, macrophage Csf-1-induced signalling increases its own expression and the expression of the matricellular protein CCN2 (formerly known as connective tissue growth factor) [37]. CCN2 is required for Col2a1 and Agc1 expression in mouse chondrocytes [38] yet does not result in hypertrophic differentiation of rat articular chondrocytes [39]. Taken together, inhibition of TNF $\alpha$-induced MEK/ ERK or downstream transcription factors may rescue cartilage ECM gene expression and promote articular cartilage regeneration through continued macrophage Csf- 1 expression.

In immortalized chondrocytes, NFKB-DNA binding activity is dependent on TNF $\alpha$-induced MEK/ERK signalling [10], consistent with studies in other immortalized cells such as B-cell lymphoma cell lines [40]. In our present study using primary chondroctyes, however, both TNF $\alpha$-regulated NFKB reporter 
Figure 5

(a) Type II collagen Proximal Promoter

-662 CCCCCGTCTACCTAGGTTTTTTTCATAGCTAGTTGGATGGGGGATGGGTTAGGGAGGCTGGGTT TGCGAGCCTCCAGGTGGGAGTTCACCGACAGGTACTCCGCAAAGGAGCTGGAAGGCAGGTCTGGAA AACTGTCCCCCAGATTTAGGATTCTGGGCAGCTTTCATCAGCTTATACTTTGGCTCCCCCGCCCCCTA AACTCCCCATCCCCACCTTCCTTTCTCCCGTTACTTCGTCCTCCCTCGCCTTTCCAGCCTTGAGTCTAA AGCTCCATGCTTATGCCTCTGCAAACAACCCCCTCCCTTCTAACCCCAGCAGAACTCCGAGGAAAGG GGCCGGAGGCCCCCCTTCTCGCCTGTGGTTAGAGGGGGCAGTGTGGCAGTCCCAAGTGGGGGCGA CCGGAGGCCGTCTCGGTGCCCCGCCCGATCAGGCCACTGGGCACATCGGGGGCGGGAAGCTGGGC TCACCAAAGGGGCGACTGGCCTTGGCAGGTGTGGGCTCTGGTCCGGCCTGGGCGGGCTCCGGGGG CGGGGTCTCAGGTTACAGCCCCGCGGGGGGCTGGGGGGCGGCCCGCGGTTTGGGCTGGTTTGCCA GCCTTTGGAGCGACCGGGAGCATATAACCGGAGCCTCTGCTGGGAGAAGACGCAGAGCGCCGCTGG $\mathrm{GCT}+1$

(b) Aggrecan Proximal Promoter -399 NNNCCCCTCCCCGCGGCCAGGGCCTGTCATTCTGACAGCAGGAGTCGGGTGCTTTCGGCACTC TGCGGGCACAGCCCTCCGGGGCCTCCTGGACTGCGGAGCTTACGACCGCAATGCAGACCCGGGTCC TCCAGCGCTACCAGCACAGCTTTCCTCCGCGGCCCCAGGAGCTGCGGGGTCCGCGCTCCTCTCGTG CCCTGCGCGCCCGGCGCCTTCCCCAGTGAGCGCGGGTCCCCAGCCCTGGTCCAGAGCGCTCCGGA CGTCTCTGCCTTCCCCTCCCCCTGCGAACTGGCCCCGGGGGTGGGGTTTCCCTGTGCGCTCGCCCC CACCCCTAGTTTGTGCCCTCCCCTCCCCCGCCCGCCCCTATGTATGTGTCACCGCGCACCATTCCCG $\mathrm{CCCA}+1$

Proximal promoters and overlapping binding regions for Sp1 and Egr-1. Proximal promoters of rat type II collagen and aggrecan, but not of link protein, have overlapping binding regions for Sp1 and Egr-1. Upstream regions of (a) the rat type II collagen, (b) aggrecan and (c) link protein were analysed by TRANSFAC [26] for transcription factor binding sites. (a) and (b) Proximal to the transcriptional start site, the type II collagen and aggrecan promoters have multiple putative Sp1 (underlined) and Egr-1 binding sites (bold), some of which are found in overlapping regions.

activity and NFKB-DNA binding were unaltered by MEK/ERK inhibition. Immortalized cells may therefore have altered signalling that activates NFKB in a MEK/ERK-dependent manner by TNF $\alpha$. Furthermore, we showed that pretreatment of primary chondrocytes with DMSO or DMSO-soluble inhibitors, such as U0124, U0126 and PD153035, reduced TNF $\alpha$-activated NFKB-DNA binding activity. The regulation of NFKB-DNA binding in primary cells can therefore be explained by the nonspecific effect of DMSO on NFKB activation.

In the present study we determined that, in addition to NFKB, TNF $\alpha$-regulated reductions in Sox9 activity were also independent of MEK/ERK signalling. Previous studies from our laboratory have shown that reductions in Sox 9 activity by TNF $\alpha$ are dependent on NFKB nuclear translocation $[10,12]$, a mechanism probably involving reductions in p300 histone acetylase activity associated with Sox9 [12]. MEK/ERK-independent reductions in Sox9 activity could therefore explain the inability of U0126 to completely reverse the TNF $\alpha$-induced reductions in cartilage ECM gene transcript levels observed in this study.

We showed that Egr-1 DNA binding was increased by TNF $\alpha$ in a U0126-sensitive fashion. Moreover, competitive inhibition of Egr-1 binding to genomic targets attenuated decreases in cartilage ECM genes in response to TNF $\alpha$. These results suggest that TNF $\alpha$ can modify gene expression in chondrocytes via MEK/ERK through the induction of Egr-1 DNA binding activity. Treatment of chondrocytes with IL-1 increases the Egr-1 protein and DNA binding, leading to decreased human type II collagen promoter activity through competition of Egr-1 for the Sp1 binding sites [31]. Previous studies have also identified that there are putative Sp1 binding sites in the aggrecan promoter of the chick, mouse and rat $[25,41]$. In this study, we identified putative overlapping binding sites for Sp1 and Egr1 in both the rat COL2A1 and AGC1 promoters proximal to the transcriptional start site. Although beyond the scope of our current report, Col2a1 and Agc1 transcription are probably regulated by inhibitory actions of Egr-1 in competition for Sp1 binding sites. Collectively, these data suggest that, in chondrocytes, alterations in Egr-1 DNA binding activity by TNF $\alpha$-induced MEK/ERK signalling is necessary for the transcriptional regulation of downstream cartilage ECM genes.

In the current study, pharmacological inhibition of MEK resulted in significant attenuation of the TNF $\alpha$-induced decreases to Col2a1, Agc1 and Hapln1 24 hours post treatment. Depending on the species the half-life of Col2a1 mRNA in chondrocytes is between 15 and 18 hours $[27,29,30]$, whereas the half-life of Agc1 mRNA is about 4 hours in bovine articular chondrocytes [28]. In this study we observed $\sim 50 \%$ reduction in Col2a1 and $\sim 70 \%$ reduction in Agc1 transcript levels after 24 hours. Previous studies from our laboratory have indicated that inhibition of Col2a1 transcripts in response to TNF $\alpha$ results from an inhibition of transcription and not from changes to message stability [10]. Furthermore, 
Figure 6

\begin{tabular}{|c|c|c|c|c|c|c|c|c|c|c|c|}
\hline U0124 & - & - & - & - & - & - & - & + & + & - & - \\
\hline U0126 & - & - & - & - & - & - & - & - & - & + & + \\
\hline TNF- $\alpha$ & - & + & + & + & + & + & + & - & + & - & + \\
\hline Sold O & - & - & egr & mut & $\kappa \mathrm{B}$ & - & - & - & - & - & - \\
\hline Antibod & - & - & - & - & - & egr & p65 & - & - & - & \\
\hline
\end{tabular}

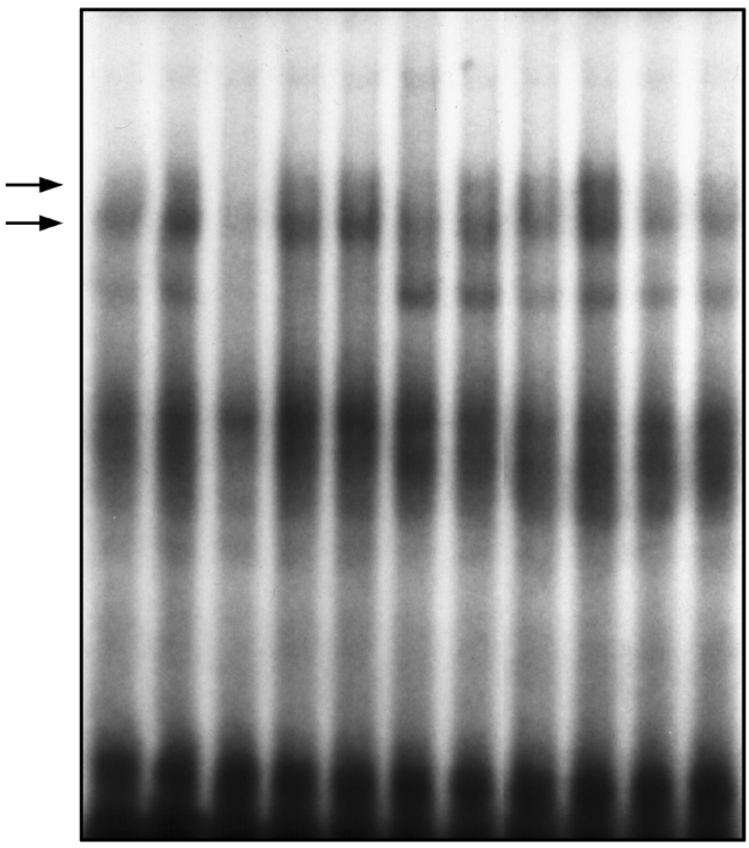

Egr-1 DNA binding activity is increased by TNF $\alpha$-induced MEK $1 / 2$ signalling in chondrocytes. Cells were pretreated with dimethyl sulfoxide, U0124 $(10 \mu \mathrm{M})$ or U0126 $(10 \mu \mathrm{M})$ for 30 minutes prior to treatment with vehicle (-) or with $30 \mathrm{ng} / \mathrm{ml}$ TNF $\alpha(+)$ for 90 minutes. Nuclear extracts were incubated with ${ }^{32} \mathrm{P}$-radiolabelled oligodeoxynucleotides corresponding to the Egr consensus DNA binding sequence. In some cases, the nuclear extracts were incubated with 100-fold excess of cold specific Egr consensus oligodeoxynucleotides (egr), mutant Egr oligodeoxynucleotides (mut) or nonspecific oligodeoxynucleotides corresponding to the $\mathrm{NF} \kappa \mathrm{B}$ consensus sequence $(\kappa \mathrm{B})$. For antibody interference assays, nuclear extracts were preincubated with specific antibody for Egr-1 (egr) or nonspecific antibody for NFKB p65 isoform (p65). Resulting protein-DNA complexes were resolved on 4\% polyacrylamide gels and exposed by autoradiography. Arrows, Egr-1-containing complexes. The autoradiograph shown is representative of three independent experiments.

treatment of chondrocytes with actinomycin $D$, a transcription inhibitor, decreased Col2a1 and Agc1 mRNAs to a level comparable with that of TNF $\alpha$ treatment alone (unpublished data). Collectively, TNF $\alpha$-induced reductions in cartilage ECM transcripts in this study are consistent with regulation of these mRNAs through inhibition of transcription. Although it is possible that TNF $\alpha$ may modulate cartilage ECM transcript expression in an indirect fashion, the relatively delayed kinetics of TNF $\alpha$-modulated cartilage ECM transcripts is probably due to the stability of the mRNAs.
Figure 7
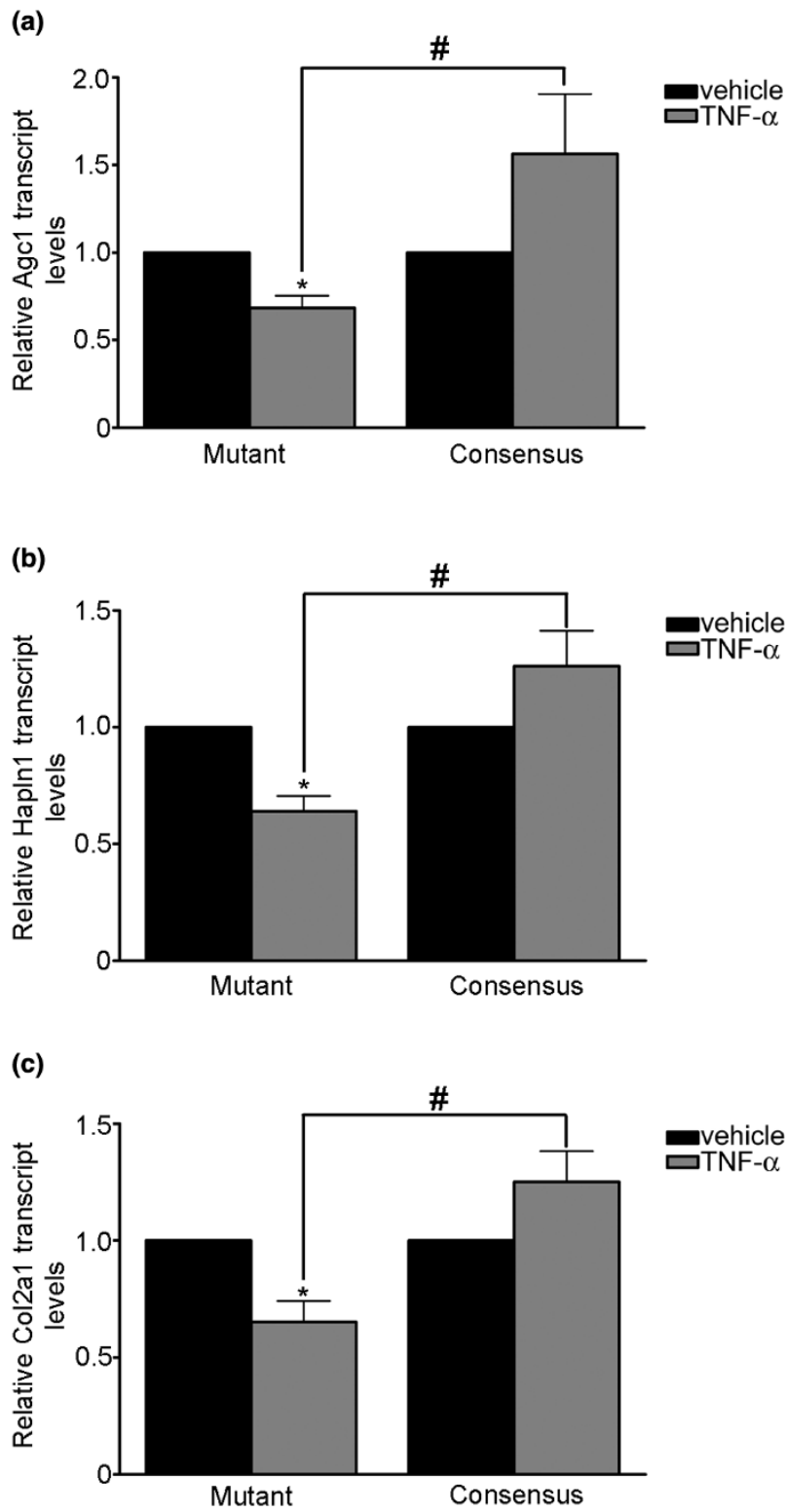

Competitive inhibition of Egr transcription factor-DNA binding attenuates TNF $\alpha$ decreases in cartilage matrix transcripts.

Chondrocytes were transfected with $2 \mu \mathrm{M}$ double-stranded, phosphorothiol-modified oligodeoxynucleotides containing Egr mutant or consensus DNA binding sequences and were treated with vehicle (black bars) or TNF $\alpha$ (grey bars) for 24 hours. Total RNA was collected and analysed by quantitative real-time PCR for (a) Agc1, (b) Hapln1 and (c) Col2a1, or $18 \mathrm{~S}$ transcript levels. Data were analysed by the $\Delta \Delta \mathrm{Ct}$ method to acquire matrix gene transcript levels relative to $18 \mathrm{~S}$. Data from cells transfected with the Egr mutant or consensus oligodeoxynucleotides were normalized to vehicle-treated cultures and were logtransformed prior to analysis by paired and Student's $t$ tests. *Significant difference ( $P<0.05$ by paired $t$ test) in transcript levels compared with vehicle-treated cells transfected with the same oligodeoxynucleotide. "Significant difference in transcript levels between cultures transfected with mutant or consensus Egr binding sequences and treated with TNF $\alpha(P<0.05$ by Student's $t$ test). Results are displayed as the mean \pm standard error of five independent experiments. 


\section{Conclusion}

Most therapies for rheumatoid arthritis, specifically biologics, are targeted towards TNF $\alpha$ protein and not towards its activated signalling pathways [42]. Targeted therapies that block specific subcellular molecules involved in TNF $\alpha$-activated signalling pathways, however, may be useful in selectively modifying chondrocyte responses to TNF $\alpha$. Our data suggest that MEK/ERK may selectively be required for TNF $\alpha$-modulated proteinase and cartilage ECM transcripts, but not for inflammatory gene transcripts. These results raise the intriguing notion that MEK/ERK inhibitors might be used to block the ability of TNF $\alpha$ to promote matrix catabolism but leave perhaps more beneficial effects of TNF $\alpha$ unaltered. In the long term, our observations may be of relevance for developing new methods of treating arthritis. In particular, antagonizing MEK/ERK or activating Egr-1 may be useful methodologies for reversing cartilage degradation observed in both osteoarthritis and rheumatoid arthritis.

\section{Competing interests}

The authors declare that they have no competing interests.

\section{Authors' contributions}

JSR carried out all aspects of the study, including the initial design of the study, microarray analysis, immunoblotting, electrophoretic mobility shift assay, quantitative real-time PCR and transfection studies, drafting and editing of the manuscript, and preparation of the figures. SMB was involved with the design and coordination of the study. AL was involved with the design and coordination of the study, drafting and editing of the manuscript.

\section{Acknowledgements}

The present study was supported by operating grants 14095 and 81243 (to SMB and AL) from the Canadian Institutes of Health Research. JSR is a recipient of a PGS D scholarship from the Natural Sciences and Engineering Research Council. The authors thank David Carter at the London Regional Genomic Centre for his help with the microarray analysis.

\section{References}

1. Eyre D: Collagen of articular cartilage. Arthritis Res 2002, 4:30-35.

2. Kiani C, Chen L, Wu YJ, Yee AJ, Yang BB: Structure and function of aggrecan. Cell Res 2002, 12:19-32.

3. Morgelin M, Heinegard D, Engel J, Paulsson M: The cartilage proteoglycan aggregate: assembly through combined proteincarbohydrate and protein-protein interactions. Biophys Chem 1994, 50:113-128.

4. Bell DM, Leung KK, Wheatley SC, Ng LJ, Zhou S, Ling KW, Sham $\mathrm{MH}$, Koopman P, Tam PP, Cheah KS: SOX9 directly regulates the type-II collagen gene. Nat Genet 1997, 16:174-178.

5. Kou I, Ikegawa S: SOX9-dependent and -independent transcriptional regulation of human cartilage link protein. J Biol Chem 2004, 279:50942-50948.

6. Sekiya I, Tsuji K, Koopman P, Watanabe H, Yamada Y, Shinomiya K, Nifuji A, Noda M: SOX9 enhances aggrecan gene promoter/ enhancer activity and is up-regulated by retinoic acid in a cartilage-derived cell line, TC6. J Biol Chem 2000, 275:10738-10744.

7. Chu CQ, Field M, Feldmann M, Maini RN: Localization of tumor necrosis factor a in synovial tissues and at the cartilage-pan- nus junction in patients with rheumatoid arthritis. Arthritis Rheum 1991, 34:1125-1132.

8. Kammermann JR, Kincaid SA, Rumph PF, Baird DK, Visco DM: Tumor necrosis factor $\alpha(\mathrm{TNF} \alpha)$ in canine osteoarthritis: immunolocalization of TNF- $\alpha$, stromelysin and TNF receptors in canine osteoarthritic cartilage. Osteoarthr Cartil 1996, 4:23-34.

9. Smith MD, Triantafillou S, Parker A, Youssef PP, Coleman M: Synovial membrane inflammation and cytokine production in patients with early osteoarthritis. J Rheumatol 1997, 24:365-371.

10. Séguin CA, Bernier SM: TNF $\alpha$ suppresses link protein and type II collagen expression in chondrocytes: role of MEK1/2 and NFkB signaling pathways. J Cell Physiol 2003, 197:356-369.

11. Klooster AR, Bernier SM: Tumor necrosis factor $\alpha$ and epidermal growth factor act additively to inhibit matrix gene expression by chondrocyte. Arthritis Res Ther 2005, 7:R127-R138.

12. Rockel JS, Kudirka JC, Guzi AJ, Bernier SM: Regulation of Sox9 activity by crosstalk with nuclear factor $-\kappa B$ and retinoic acid receptors. Arthritis Res Ther 2008, 10:R3.

13. Carames B, Lopez-Armada MJ, Cillero-Pastor B, Lires-Dean M, Vaamonde C, Galdo F, Blanco FJ: Differential effects of tumor necrosis factor-alpha and interleukin-1beta on cell death in human articular chondrocytes. Osteoarthr Cartil 2008, 16:715-722.

14. MacEwan DJ: TNF receptor subtype signalling: differences and cellular consequences. Cell Signal 2002, 14:477-492.

15. Hildt $E$, Oess $S$ : Identification of Grb2 as a novel binding partner of tumor necrosis factor (TNF) receptor I. J Exp Med 1999, 189:1707-1714.

16. Hedberg A, Messner K, Persliden J, Hildebrand C: Transient local presence of nerve fibers at onset of secondary ossification in the rat knee joint. Anat Embryol (Berl) 1995, 192:247-255.

17. Favata MF, Horiuchi KY, Manos EJ, Daulerio AJ, Stradley DA, Feeser WS, Van Dyk DE, Pitts WJ, Earl RA, Hobbs F, Copeland RA, Magolda RL, Scherle PA, Trzaskos JM: Identification of a novel inhibitor of mitogen-activated protein kinase kinase. J Biol Chem 1998, 273:18623-18632.

18. Davies SP, Reddy H, Caivano M, Cohen P: Specificity and mechanism of action of some commonly used protein kinase inhibitors. Biochem J 2000, 351:95-105.

19. Fry DW, Kraker AJ, McMichael A, Ambroso LA, Nelson JM, Leopold WR, Connors RW, Bridges AJ: A specific inhibitor of the epidermal growth factor receptor tyrosine kinase. Science 1994, 265:1093-1095.

20. Dignam JD, Lebovitz RM, Roeder RG: Accurate transcription initiation by RNA polymerase II in a soluble extract from isolated mammalian nuclei. Nucleic Acids Res 1983, 11:1475-1489.

21. Kudirka JC, Panupinthu N, Tesseyman MA, Dixon SJ, Bernier SM: P2Y nucleotide receptor signaling through MAPK/ERK is regulated by extracellular matrix: involvement of $\beta 3$ integrins. $J$ Cell Physio/ 2007, 213:54-64.

22. Weston AD, Chandraratna RA, Torchia J, Underhill TM: Requirement for RAR-mediated gene repression in skeletal progenitor differentiation. J Cell Biol 2002, 158:39-51.

23. Lefebvre V, Zhou G, Mukhopadhyay K, Smith CN, Zhang Z, Eberspaecher H, Zhou X, Sinha S, Maity SN, de Crombrugghe B: An 18-base-pair sequence in the mouse proa1(II) collagen gene is sufficient for expression in cartilage and binds nuclear proteins that are selectively expressed in chondrocytes. Mol Cell Biol 1996, 16:4512-4523.

24. Kohno K, Sullivan M, Yamada Y: Structure of the promoter of the rat type II procollagen gene. J Biol Chem 1985, 260:4441-4447.

25. Watanabe H, Gao L, Sugiyama S, Doege K, Kimata K, Yamada Y: Mouse aggrecan, a large cartilage proteoglycan: protein sequence, gene structure and promoter sequence. Biochem $J$ 1995, 308(Pt 2):433-440.

26. Matys V, Kel-Margoulis OV, Fricke E, Liebich I, Land S, Barre-Dirrie A, Reuter I, Chekmenev D, Krull M, Hornischer K, Voss N, Stegmaier $P$, Lewicki-Potapov $B$, Saxel $H$, Kel AE, Wingender $E$ : TRANSFAC and its module TRANSCompel: transcriptional gene regulation in eukaryotes. Nucleic Acids Res 2006, 34:D108-D110.

27. Askew GR, Wang S, Lukens LN: Different levels of regulation accomplish the switch from type II to type I collagen gene 
expression in 5-bromo-2' -deoxyuridine-treated chondrocytes. $J$ Biol Chem 1991, 266:16834-16841.

28. Curtis AJ, Devenish RJ, Handley CJ: Modulation of aggrecan and link-protein synthesis in articular cartilage. Biochem J 1992, 288(Pt 3):721-726.

29. Galera P, Redini F, Vivien D, Bonaventure J, Penfornis H, Loyau G, Pujol JP: Effect of transforming growth factor- $\beta 1$ (TGF- $\beta 1$ ) on matrix synthesis by monolayer cultures of rabbit articular chondrocytes during the dedifferentiation process. Exp Cell Res 1992, 200:379-392.

30. Goldring MB, Fukuo K, Birkhead JR, Dudek E, Sandell LJ: Transcriptional suppression by interleukin-1 and interferongamma of type II collagen gene expression in human chondrocytes. J Cell Biochem 1994, 54:85-99.

31. Tan L, Peng H, Osaki M, Choy BK, Auron PE, Sandell LJ, Goldring MB: Egr-1 mediates transcriptional repression of COL2A1 promoter activity by interleukin-1 $\beta$. J Biol Chem 2003, 278:17688-17700.

32. Fosang AJ, Neame PJ, Last K, Hardingham TE, Murphy G, Hamilton JA: The interglobular domain of cartilage aggrecan is cleaved by PUMP, gelatinases, and cathepsin B. J Biol Chem 1992, 267:19470-19474.

33. Gronski TJ Jr, Martin RL, Kobayashi DK, Walsh BC, Holman MC, Huber M, Van Wart HE, Shapiro SD: Hydrolysis of a broad spectrum of extracellular matrix proteins by human macrophage elastase. J Biol Chem 1997, 272:12189-12194.

34. Chandler S, Cossins J, Lury J, Wells G: Macrophage metalloelastase degrades matrix and myelin proteins and processes a tumour necrosis factor- $\alpha$ fusion protein. Biochem Biophys Res Commun 1996, 228:421-429.

35. Itoh T, Matsuda H, Tanioka M, Kuwabara K, Itohara S, Suzuki R: The role of matrix metalloproteinase- 2 and matrix metalloproteinase-9 in antibody-induced arthritis. J Immunol 2002, 169:2643-2647.

36. Campbell IK, lanches G, Hamilton JA: Production of macrophage colony-stimulating factor (M-CSF) by human articular cartilage and chondrocytes. Modulation by interleukin-1 and tumor necrosis factor $\alpha$. Biochim Biophys Acta 1993, 1182:57-63.

37. Nakao K, Kubota S, Doi H, Eguchi T, Oka M, Fujisawa T, Nishida T, Takigawa M: Collaborative action of M-CSF and CTGF/CCN2 in articular chondrocytes: possible regenerative roles in articular cartilage metabolism. Bone 2005, 36:884-892.

38. Nishida T, Kawaki $H$, Baxter RM, Deyoung RA, Takigawa M, Lyons $\mathrm{KM}$ : CCN2 (connective tissue growth factor) is essential for extracellular matrix production and integrin signaling in chondrocytes. J Cell Commun Signal 2007, 1:45-58.

39. Nishida T, Kubota S, Nakanishi T, Kuboki T, Yosimichi G, Kondo S, Takigawa M: CTGF/Hcs24, a hypertrophic chondrocyte-specific gene product, stimulates proliferation and differentiation, but not hypertrophy of cultured articular chondrocytes. J Cell Physiol 2002, 192:55-63.

40. Kurland JF, Voehringer DW, Meyn RE: The MEK/ERK pathway acts upstream of NFkB1 (p50) homodimer activity and Bcl-2 expression in a murine B-cell lymphoma cell line. MEK inhibition restores radiation-induced apoptosis. J Biol Chem 2003, 278:32465-32470.

41. Pirok EW 3rd, Li H, Mensch JR Jr, Henry J, Schwartz NB: Structural and functional analysis of the chick chondroitin sulfate proteoglycan (aggrecan) promoter and enhancer region. J Biol Chem 1997, 272:11566-11574.

42. Lorenz HM, Kalden JR: Perspectives for TNF- $\alpha$-targeting therapies. Arthritis Res 2002, 4(Suppl 3):S17-S24. 